\title{
INTESTINAL OBSTRUCTION CAUSED BY RETAINED SURGI- CAL SPONGE: TWO CASE REPORTS
}

\author{
"N.A. ADU-ARYEE, E. ASUMANU, A. TETTEH, E. FORDJOUR AND S.B. NAAEDER \\ Departments of Surgery and Anaesthesia, Korle Bu Teaching Hospital, P.O. Box 77, Acera, Ghana.
}

\section{SUMMARY}

We present two cases of intestinal obstruction from retained laparotomy packs and their management. Attention to detail in theatre procedure should reduce such occurrence.

\section{INTRODUCTION}

Retention of sponges in the peritoncal cavity after laparotomy is an avoidable complication which unfortunately still occurs. Various methods including radio opaque markers have been used to try and minimize this occurrence or to ensure its carly detection. Adherence to theater protocol such as counting packs betore and after surgery remains the most useful in the sub-region as theatre X-ray facilities may not be available to detect retained packs.

\section{Case 1}

A 39-ycar-old woman with a lower midline incisional hernia was seen in the emergency room with a day's history of colicky abdominal pain and vomiting. She had experienced similar episodes in the preceding 6 months associated wilh incisional herniation and for which she had sought no medical help. The patient had an emergency caesarcan section for failed induction of labour 10 months earlier.

On examination she was in moderate discomfort, her blood pressure was $153 / 113 \mathrm{mmHg}$, the heart rate was 75 beats $/$ min and temperature $36^{\circ} \mathrm{C}$. Her abdomen was not distended and the incisional hernia was easily reducible. A tender mass initially palpated in the left iliac fossa was later palpated in the right iliac fossa on repeated examination. Bowel sounds were increased in firequency and pitch. Vaginal examination confirmed the presence of a right adnexal mass with a normal sized uterus shifted to the left. The rectum was empty on digital rectal examination. A preliminary diagnosis of intestinal obstruction caused by adhesions was made.
Her leukocyte count was $14.5 \times 10^{9}$ with a neutrophilia of $87 \%$. Plain abdominal $x$-rays revealed distended loops of bowel suggestive of smal] bowel obstruction possibly due to adhesions. Abdominal ultrasonography showed a normal sized uterus and cervix. The right ovary could not be identified but in its place, a hypoechoic mass of $8 \times 8 \mathrm{~cm}$ was found. The left ovary was normal.

An emergency laparotomy was performed because the symptoms did not resolve over the next 24 hours. At operation multiple adhesions between loops of bowel were found.

An intraluminal ileal mass about $40 \mathrm{~cm}$ from the ileocaecal valve was found to be the cause ol obstruction. The right ovary was normal. Enteroiomy revealed an intact laparotomy towel (Figure 1). The enterotomy was closed in two layers and the hernia repaired. The patient made an uneventful recovery and was discharged on the tenth postoperative day. She was seen weeks postoperatively will no complains.

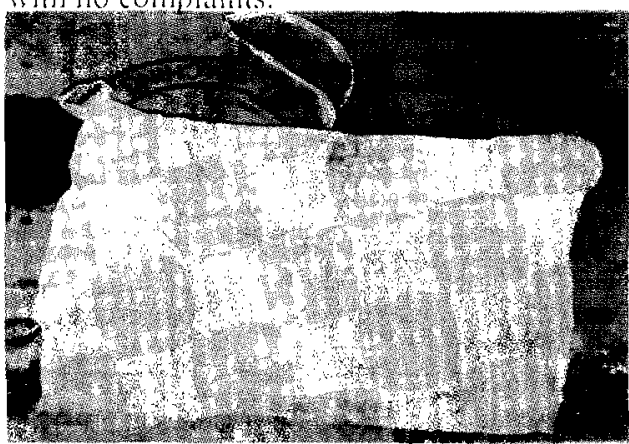

Figure I Laparotony towel

\section{Case 2}

A 33 ycar-old woman was admitted to the emergency department with a 3-day history of vomiting, constipation and left upper quadrant abdomiai pain. The vomit was bile-stained and contained undigested food. This was followed a day later by absolute constipation. The patient had had a laparotomy 5 months earlier following a road traffic

\footnotetext{
* Author for correspondence
} 
accident in which she suffered liver laceration and had intra-abdominal packs placed in order to control haemorrhage. The abdominal packs were presumably all removed as bleeding was controlled at the end of the procedure and there was no record of a "second look" operation.

On the examination she looked ill and dehydrated with a heart rate of 100 beats/min, blood pressure of $100 / 60 \mathrm{mmHg}$ and a temperature of $37.2^{\circ} \mathrm{C}$. Her abdomen had an upper midline scar, was not tender and had a palpable mass in the left hypochondrium. Bowel sounds were increased in frequency and pitch.

Her white cell count was $21.7 \times 10^{9}$ with $65 \%$ neutrophils. Plain $x$-rays of her abdomen showed small bowel air fluid levels and a radio-opaque mass suggestive of a retained abdominal pack (rayon marker).

An emergency laparotomy was performed to relicve presumed adhesions and to retricve the pack. At surgery several of the small bowel adhesions were found and lysed but were not thought to be the cause of the obstruction. An intraluminal foreign body was found to be the cause of the obstruction about $30 \mathrm{~cm}$ from the ileocaccal valve. A laparotomy sponge was retricved through an entcrotomy, which was closed in two layers. The patient was discharged on the tenth postoperative day, has been reviewed at three and six months post operatively and she remains well.

\section{DISCUSSION}

Intestinal obstruction remains a major indication for emergency surgery in Ghana'. Foreign bodies are listed as a rare cause of intestinal obstruction. The commonest foreign body causing intestinal obstruction remains laparotomy sponges ${ }^{2}$. Other foreign bodies include vaginal pessaries ${ }^{3}$, surgical drains ${ }^{4}$, vascular grafts, migrating Angelchik prosthesis $^{6}$ and ventriculaoperitoneal shunts ${ }^{7}$. There is a single case report of a metallic ring being left for over 40 years before becoming symptomatic ${ }^{8}$. The interval after which a retained laparotomy sponge becomes symptomatic may be determined by its position in the peritoneal cavity".

Crossen in 1940 reported that extrusions into hollow viscera may occur into the intestinal lumen, rectum, vagina or bladder ${ }^{10}$.

Both cases presented in this report had symptoms of intestinal obstruction within one year of the pack being retained. The mechanism was probably through slow pressure necrosis of the bowel wall with migration of the sponge into the lumen and sealing off of the wall with minimal peritoncal soiling. There have been anecdotal reports of this in Ghana but this appears to be the first documentation of this event at the Korle Bu Teaching Hospital. It is important that we pay attention to detail in order to minimize these occurrences.

Swab and instrument count should be done beforc any wound is closed.

\section{REFERENCES}

1. Naaeder SB, Tandoh JK. Intestinal obstruction. In: Badoc EA, Archampong EQ, da Rocha-A fodu JT (eds). Principles and practice of surgery including pathology in the tropics. Department of Surgery, University of Ghana Medical School. 2000; 34: 529.

2. Kaiser $\mathrm{CW}$, Firedman $\mathrm{S}$ et al. The retained surgical sponge. Ann Surg 1996; 224(1): 7984.

3. Lukomski L. Rare case of mechanical obstruction occlusion of intestine due to pessary. Pol Tyg Lek 1971; 26(31): 1202-1203.

4. Van Hee R. Complications of drainage. Acta Chir Belg 1983; 83(11): 340-344.

5. Jarret F, Hirsch S.A., Steed D, Boehnke M. Small-bowel obstruction caused by intraluminal migration of prosthetic gralts. $J$ Vasc Surg 1985; 2 (3): 477-479.

6. Arpayaglou A, Jansen AJ. Migration of Angelchick prosthesis and small bowel obstruction. J Arkansas Med Soc 1987; 83(11): 437. 438 .

7. Lortat-Jacob S, Pierre-Kahn A, Renier D, Hirsch JF, Martelli H, Pellerin D. Abdominal complications of ventriculo-peritoneal shunts in children - 65 cases. Chir Pediatr 1984; 25(11): 17-21.

8. Quantz MA, Brown R. Late presentation of an intra abdominal foreign body. Can $J$ Surg 1997; 40(4): 305-307.

9. Rymer CA, McCarthy JD. A silent sponge speaks. Am J of Surg 1974; 128: 103-104.

10. Crossen HS, Crossen DF. Foreign bodies left in the abdomen. St Louis, Mosby, 1940. 